\title{
The effects of knee extensor eccentric training on functional tests in healthy subjects
}

\author{
Os efeitos do treino isocinético excêntrico dos extensores do joelho nos testes \\ funcionais em sujeitos saudáveis
}

Heleodório H. Santos', Mariana A. Ávila², Daniela N. Hanashiro², Paula R. Camargo², Tania F. Salvini²

\begin{abstract}
Background: It is well known that eccentric training increases muscle strength and promotes greater neural activation, and therefore has been used in the recovery of knee extensors. The hypothesis of this study was that there would be a strong correlation between knee extensor torque and functional tests. Objectives: To investigate the relationship between knee extensor peak torque and functional tests of agility (runs) and propulsion (hop for distance) after short-term isokinetic eccentric training. Methods: Twenty healthy and active male undergraduate students (age $22.5 \pm 2.1$ years; height $1.72 \pm 0.10 \mathrm{~m}$; weight $67.8 \pm 9.5 \mathrm{~kg}$; body mass index: $22.5 \pm 2.0 \mathrm{~kg} / \mathrm{m}^{2}$ ), with no abnormalities or history of injury of the limbs, performed an isokinetic assessment of the knee extensors and flexors and also functional tests before and after isokinetic training, which consisted of 3 sets of 10 MVECs at 30\%, with 3 minutes of rest between sets, twice a week for 6 weeks. Results: The eccentric training increased the extensor peak torque (16, 27 and 17\%; P<0.01) and decreased the $\mathrm{H} / \mathrm{Q}$ ratio $(10,20$ and $13 \% ; \mathrm{P}<0.01)$ for the isometric and eccentric modes at $30 \%$ s and $120 \%$, respectively. It also decreased the time in two of the five agility tests (carioca and pivot diagonal; $\mathrm{P}<0.01$ ), and increased the distance in the hop tests, for both dominant and non-dominant limbs $(P<0.01)$. Conclusions: Although the eccentric training led to an increase in extensor peak torques as well as an improvement in most of the functional tests, the hypothesis that a strong correlation would be observed between peak torques and functional tests was not confirmed.
\end{abstract}

Article registered in the Australian New Zealand Clinical Trials Registry (ANZCTR) under the number 12607000590460.

Keywords: hop tests; agility tests; torque; knee; eccentric training; $H / Q$ ratio.

\section{Resumo}

Contextualização: Sabe-se que o treino excêntrico aumenta a força muscular, promovendo uma maior ativação neural e, portanto, tem sido usado na recuperação do torque extensor. A hipótese deste estudo foi a de que possa existir uma forte correlação entre o torque extensor do joelho e os testes funcionais. Objetivos: Correlacionar o torque extensor do joelho com os testes funcionais de agilidade (corridas) e impulsão (saltos em distância) após o treino isocinético excêntrico de curta duração. Métodos: Vinte homens universitários,

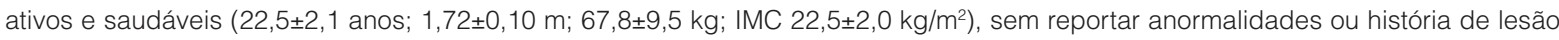
no membro inferior, realizaram avaliação isocinética do torque extensor e flexor do joelho e testes funcionais antes e depois do treino isocinético que consistiu em três séries de $10 \mathrm{CEVM}$ a 30\%, com 3 minutos de repouso entre as séries, realizado duas vezes por semana, durante seis semanas. Resultados: O torque extensor aumentou (16, 27 e 17\%; P<0,01), a razão I/Q diminuiu (10, 20 e 13\%; $\mathrm{p}<0,01)$ para os modos: isométrico e excêntrico a $30 \%$ e $120 \%$, respectivamente; diminuiu o tempo em dois dos cinco testes de corridas (carioca e pivô diagonal; $\mathrm{P}<0,01$ ) e aumentou a distância nos testes de saltos tanto para o membro dominante quanto para o não dominante $(P<0,01)$. Conclusões: Embora o treino excêntrico tenha aumentado o torque dos extensores do joelho, bem como melhorado a maioria dos testes funcionais, a hipótese de uma forte correlação entre essas variáveis não se confirmou. Artigo registrado no Australian New Zealand Clinical Trials Registry (ANZCTR) sob o número 12607000590460.

Palavras chave: testes de saltos; testes de agilidade; torque; joelho; treino excêntrico; razão I/Q

Received: 06/10/2008 - Revised: 22/04/2009 - Accepted: 15/09/2009

${ }_{1}$ Physical Therapy Department, Universidade Federal da Paraíba (UFPB), João Pessoa (PB), Brazil

${ }^{2}$ Physical Therapy Department, Universidade Federal de São Carlos (UFSCar), São Carlos (SP), Brazil

Correspondence to: Tania de Fátima Salvini, Departamento de Fisioterapia, Universidade Federal de São Carlos, Rodovia Washington Luis, Km 235, CP 676, CEP 13565-905,

São Carlos (SP), Brazil, e-mail: tania@ufscar.br 


\section{Introduction $: \therefore$.}

Due to its anatomic and functional characteristics, the knee is one of the most overloaded joints in the musculoskeletal system ${ }^{1}$. Many studies have demonstrated the effectiveness of resistance training ${ }^{2}$ in improving physical performance and treating musculoskeletal injuries to this joint ${ }^{1,3,4}$. Because eccentric exercise promotes greater neural activation compared to isometric and concentric contractions ${ }^{5}$, it is considered to be a powerful stimulus to hypertrophy ${ }^{6}$ and muscle strength ${ }^{7}$. However, the extent of these morphofunctional changes depends on the intensity, frequency and duration of training $\mathrm{g}^{8,9}$.

Regular exercise programs with heavy loads have led to muscle hypertrophy, but the strength gain acquired before the hypertrophy has been attributed to increased neural activity ${ }^{10}$. Widrick et al. ${ }^{11}$ observed an increase of more than $60 \%$ in the strength of the vastus lateralis muscle after short-term resistance training, which changed the muscle's functional properties. Some studies that evaluated the knee flexors and extensors recorded higher torque during the eccentric $^{12,13}$ and concentric ${ }^{14}$ contraction, respectively, at low speeds.

The most common tool to evaluate the effects of resistance training is isokinetic dynamometry because it allows the control of significant movement variables, such as range of motion, angular velocity, work load, exercise mode (isometric, concentric or eccentric) and identifies the agonist/antagonist ratio ${ }^{1,2,4,13,15,16}$. Additionally, the functional tests of agility (runs) and hop for distance ${ }^{17-19}$ provide security and efficiency parameters, being extensively used to assess the athlete's capacity to resume training after injury ${ }^{20}$.

Although these functional tests are considered reliable $(>80 \%)$ and sensitive (>82\%), their relationship with the muscle torque of knee extensors and flexors is still controversial in the literature ${ }^{21}$, given that the methodologies differ in: concentric ${ }^{2,15,22-24}$ and/or eccentric mode $\mathrm{e}^{13,16,25}$; velocity of movement $\left(30,60,70,90,120,150,180,240,270,300 \text { and } 400^{\circ} / \mathrm{s}\right)^{13,16,25}$ and muscle group (extensors ${ }^{25,26}$ and/or flexors ${ }^{2,13,15,16}$ ).

In light of the above considerations, the hypothesis of the present study was that the strengthening of knee extensors would lead to an improvement in joint function, which could be evidenced by the agility and hop for distance tests. Due to the fact that eccentric movement at low speed generates higher torque than the other contraction modes ${ }^{12-14}$, this study analyzed the short-term effects of isokinetic eccentric training at low speed $\left(30^{\circ} / \mathrm{s}\right)$ on the knee extensors in healthy subjects with the aim of verifying a possible linear correlation between knee torque and performance in functional tests.

\section{Methods : :}

\section{Subjects}

The initial sample consisted of 25 healthy and active male undergraduate students selected from a school of physical therapy. Five of them were excluded from the study: three due to knee pain during training and two due to absence. A total of 20 subjects completed the study (age 22.5 \pm 2.1 years; height $1.72 \pm 0.10 \mathrm{~m}$; weight $67.8 \pm 9.5 \mathrm{~kg}$; body mass index $/ \mathrm{BMI} 22.5 \pm 2.0 \mathrm{~kg} / \mathrm{m}^{2}$ ). After answering a questionnaire, the subjects were selected according to the following criteria: a) no regular muscle strength training; b) BMI below $24 \mathrm{~kg} / \mathrm{m}^{2}$; and 3) no musculoskeletal injuries or balance disorders (Lachman test, varus and valgus tests at 0 and $30^{\circ}$ ).

The study was conducted in accordance with the Human Research Ethics Committee of Universidade Federal de São Carlos (UFSCar), São Carlos (SP), Brazil, and all subjects signed an informed consent form (approval number 144/2004 - CEP/UFSCar).

\section{Torque evaluation}

The dominant leg (right=5; left=15) was identified before the torque evaluation by asking the subject which leg he would use to kick a ball and by asking the subject to hop over an obstacle. The tests were conducted on the non-dominant leg because it is the one used for postural support and propulsion ${ }^{27,28}$. Initially, the subjects warmed up on a stationary bicycle ( $75 \mathrm{~W}$ ) for $5 \mathrm{~min}$ at $20 \mathrm{~km} / \mathrm{h}$, followed by a set of three $30-\mathrm{s}$ stretches (followed by 30-s intervals) focused on knee flexors, knee extensors and plantar flexors. Next, the subjects were positioned in an isokinetic dynamometer (Biodex Multi-Joint System 3, Shirley, NY) with the backrest reclined $5^{\circ}$ from vertical and knees flexed at $90^{\circ}$. To avoid compensatory movements, straps were positioned across the subject's trunk, pelvis, and thigh. The dynamometer axis was aligned with the axis of rotation of the knee joint (lateral femoral epicondyle) and the dynamometer lever arm was attached to the distal leg ( $5 \mathrm{~cm}$ above the medial malleolus) so as to allow full ankle dorsiflexion ${ }^{29}$. The familiarization period consisted of three submaximal eccentric contractions of the knee extensors, followed by a 3-min rest period. The effect of gravity on torque was corrected with the knee flexed at $60^{\circ}$, and the adjustment for correction was calculated by using the instrument's software, according to Dvir ${ }^{29}$.

The knee extensor and flexor torques were evaluated under isometric and eccentric isokinetic $\left(30^{\circ} / \mathrm{s}\right.$ and $\left.120^{\circ} / \mathrm{s}\right)$ conditions. To measure the maximal isometric torque, the dynamometer lever arm was fixed at $60^{\circ}$ for knee extension ${ }^{25}$ and at $30^{\circ}$ for knee flexion ${ }^{30}$. The evaluation consisted of one set of three 
maximal voluntary isometric contractions (MVIC) lasting 5s each, with 1-min rest intervals ${ }^{31}$. The mean peak torque (MPT) of the three contractions was calculated for each subject ${ }^{7,8}$.

The range of motion ( $\mathrm{ROM})$ for the eccentric isokinetic evaluations was set to $70^{\circ}$ (extension from $20^{\circ}$ to $90^{\circ}$, and flexion from $90^{\circ}$ to $\left.20^{\circ}\right)$. Each test $\left(30^{\circ} / \mathrm{s}\right.$ and $\left.120^{\circ} / \mathrm{s}\right)$ consisted of one set of five consecutive maximal voluntary eccentric contractions (MVEC) with a 1-min rest period between velocities ${ }^{29}$. The MPT obtained for the 5 contractions of knee extensors and flexors was calculated at the end of each set.

During the evaluations and training, the subjects received verbal stimulation provided by the same examiner in a standardized manner to encourage maximal contraction. Additionally, the subjects were provided with visual feedback displayed as a graph on the instrument's screen ${ }^{22}$. The conventional hamstring/quadriceps (H/Q) ratio was calculated by dividing the flexor peak torque by the extensor peak torque and multiplying this result by $100^{32}$ for all contraction modes (isometric and eccentric) and velocities (30\% $/ \mathrm{s}$ and $\left.120^{\circ} / \mathrm{s}\right)$.

\section{Isokinetic training}

Prior to each training session, the equipment was calibrated and the subjects underwent the same warm-up and stretch protocols as previously described. Afterwards, they followed an eccentric (bilateral) training protocol focused on the strengthening of the knee extensors. This consisted of three sets of $10 \mathrm{MVECs}^{23}$ at $30^{\circ} / \mathrm{s}$, with a $3-\mathrm{min}$ rest period between sets. Studies that examined eccentric contraction in the knee flexors and extensors at

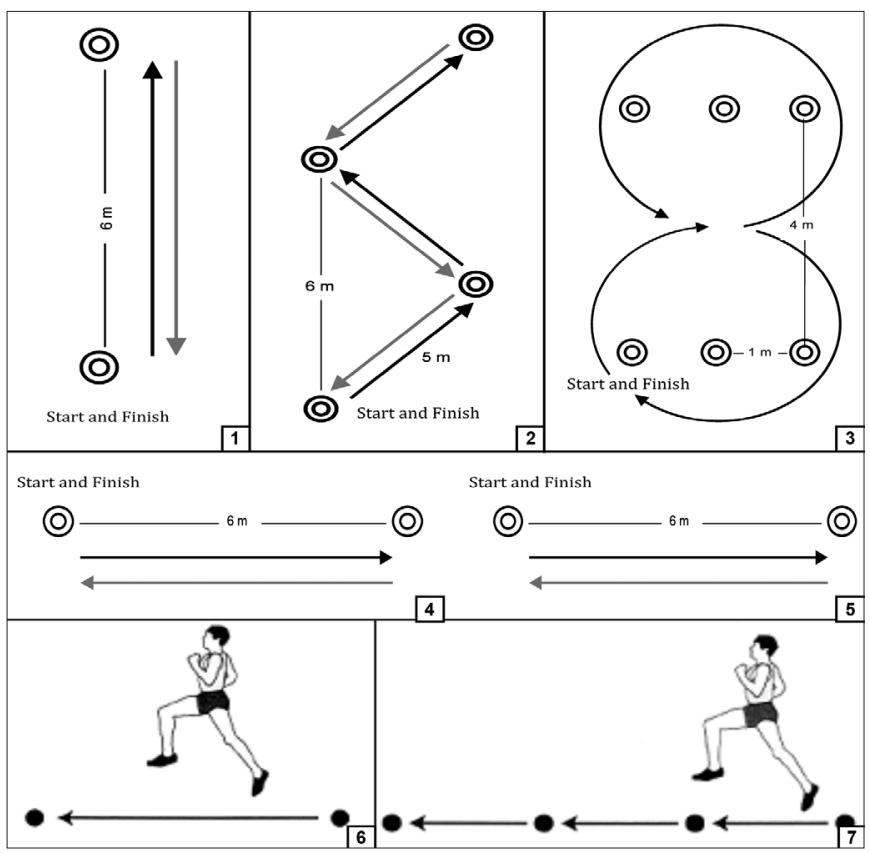

Figure 1. Functional tests: shuttle run (1); pivot diagonal run (2); figure-eight run (3); lateral run (4); carioca (5); single hop (6); triple hop (7). low speeds ${ }^{13,16}$ found higher torque. Training was performed twice a week for six weeks (12 sessions), alternating dominant and nondominant limbs, with an interval of at least $48 \mathrm{~h}$ between sessions.

\section{Functional tests}

Initially, the subjects performed a brief warm-up that consisted of running around the court at low velocity (trotting) for 5 minutes. Afterwards, they followed the same stretch protocol as the one used for torque evaluations. Functional tests were carried out before and after the eccentric isokinetic training of the knee extensors (pre- and post-training) and consisted of five agility tests (shuttle run, lateral run, carioca, pivot diagonal run and figure-eight) at maximal velocity, and two hop for distance tests (single and triple). One- and two-min rest intervals were allowed between the sets of the agility and hop tests, respectively.

For the shuttle and lateral runs, and carioca, a 6-m distance was marked with two cones placed one in front of the other. In the shuttle run (Figure 1.1), the subjects were instructed to run back and forth. For the pivot diagonal run (zigzag), two parallel columns were demarcated by two cones on each side, keeping a 6-m distance between the cones on the same side and a $5 \mathrm{~m}$ distance between the cones on opposite sides placed diagonally (Figure 1.2). The subjects were instructed to run from one cone to the opposite cone, then turn around (pivot) to the right or the left, alternately, and run diagonally toward another cone, thus completing a distance of $15 \mathrm{~m}^{33}$. For the figure-eight run (Figure 1.3), two parallel columns were placed $4 \mathrm{~m}$ apart. Each column was formed by three cones positioned $1 \mathrm{~m}$ apart. The subjects were instructed to run around the two columns so as to form a figure eight ${ }^{33,34}$. The lateral run (Figure 1.4) was in a straight line, but the subjects had to run sideways from right to left (round trip). In the carioca (Figure 1.5), the displacement was also performed sideways from right to left, but the subjects used a cross over step, alternating one leg in front of the other ${ }^{18,19}$. In all agility tests, verbal commands (i.e. "ready, set, go!") were given to the subjects with the aim of standardizing the beginning of the test and the time-keeping process.

For the hop for distance tests (single and triple), the subjects were instructed to stand on one foot, behind the starting line, find their balance and then perform the hop when they felt ready. For the single hop for distance test (Figure 1.6), the distance between the starting point and the landing point of the tested foot was measured $^{35-39}$. For the triple hop for distance test (Figure 1.7), the same procedure was used to calculate the distance relative to three consecutive hops ${ }^{18,19,40}$. For each type of hop, three attempts were performed, alternating right and left legs.

In both pre- and post-training, all subjects performed the functional tests (agility and hop for distance) in the same 
sequence (runs: shuttle, lateral, carioca, pivot diagonal and figure-eight; hop for distance test: single and triple). For the post-training, a 72-h interval was allowed after the last session of isokinetic training. With the purpose of standardizing the procedures, all the tests were initiated by the non-dominant limb. Three attempts were performed for each of the functional tests of agility and horizontal propulsion, and the means of the three attempts were calculated for both time and distance variables.

\section{Data analysis}

The Statistical Package for the Social Sciences (SPSS) was used for the statistical analysis (mean, standard deviation, paired t-test, Wilcoxon, one-way ANOVA, and ICC). The MPT and the variance of the conventional $\mathrm{H} / \mathrm{Q}$ ratio for peak torque were analyzed for all modes and velocities evaluated in pre- and post-training. The functional tests were used to investigate the differences between pre- and post-training means and to investigate a possible relationship with MPT (ICC). With regard to the correlation tests (ICC), values ranging from 0 to 0.5 were considered weak, values ranging from 0.51 to 0.75 were considered moderate, and values above 0.75 were considered strong. A significance level of $5 \%(\mathrm{P}<0.05)$ was used for all analyses.

\section{Results $: \therefore$.}

\section{Isokinetic dynamometry}

\section{MPT}

For the comparisons of MPT for knee extensors between pre- and post-training, there was a gain of $16 \%(\mathrm{P}<0.01)$ for the isometric mode, $27 \%(\mathrm{P}<0.01)$ for the eccentric mode at $30^{\circ} / \mathrm{s}$ and $17 \%(\mathrm{P}<0.01)$ at $120 \%$ s. Also, the knee flexors had an increase of $8 \%(\mathrm{P}<0.05)$ for MPT in the eccentric mode at $30^{\circ} / \mathrm{s}$, although this mode did not compose the training protocol (Table 1).

\section{Time to peak torque (TPT)}

In general, the means of the TPT tended to decrease, although it was only statistically significant in the eccentric mode at $30^{\circ} / \mathrm{s}(\mathrm{P}<0.01$; Table 2$)$.

\section{Hamstring/Quadriceps Ratio (H/Q)}

As shown in Table 3, there was a significant decrease in the conventional $\mathrm{H} / \mathrm{Q}$ ratio after training in all modes and velocities analyzed, but the greatest decrease percentage $(20 \%)$ was observed in the eccentric mode at $30^{\circ} / \mathrm{s}$, followed by the eccentric mode at $120^{\circ} / \mathrm{s}(13 \%)$, and the isometric mode (10\%).

The one-way ANOVA test showed that the training protocol used in the study increased the difference in the H/Q ratio between contraction modes. For pre-training, there was a difference between isometric mode and eccentric mode at $120^{\circ} / \mathrm{s}(\mathrm{P}<0.05)$. For post-training, there was a difference between isometric mode and eccentric mode at $30^{\circ} / \mathrm{s}(\mathrm{P}<0.05)$, and a difference between the velocities of $30^{\circ} / \mathrm{s}$ and $120^{\circ} / \mathrm{s}$ in the eccentric mode $(\mathrm{P}<0.01)$.

Table 1. Comparisons of the means of peak torque ( $\mathrm{Nm}$ ) before and after 6 weeks of isokinetic eccentric training of the knee extensors.

\begin{tabular}{lcccc}
\hline \multirow{2}{*}{ Torque } & \multicolumn{4}{c}{ Mean of peak torque (Nm) } \\
\cline { 2 - 5 } & Pre-training & Post-training & $\begin{array}{c}\text { t-test } \\
\text { (paired) }\end{array}$ & $\begin{array}{c}\text { Gain } \\
(\%)\end{array}$ \\
\hline Extensors & & & & \\
\hline Isometric & $217.5 \pm 42.5$ & $259.3 \pm 51.2^{* *}$ & 0.0001 & 16 \\
\hline Eccentric $30^{\circ} / \mathrm{s}$ & $232.2 \pm 55.9$ & $318.8 \pm 55.6^{\star *}$ & $<0.0001$ & 27 \\
\hline Eccentric $120 \%$ & $215.7 \pm 50.4$ & $259.8 \pm 67.4^{* *}$ & 0.0001 & 17 \\
\hline Flexors & & & & \\
\hline Isometric & $108.7 \pm 27.1$ & $115.1 \pm 32.2$ & 0.0587 & 6 \\
\hline Eccentric $30^{\circ} / \mathrm{s}$ & $113.9 \pm 28.4$ & $123.3 \pm 20.8^{*}$ & 0.0159 & 8 \\
\hline Eccentric $120^{\circ} / \mathrm{s}$ & $108.3 \pm 29.8$ & $111.8 \pm 31.2$ & 0.2380 & 3 \\
\hline Nm=Newton.meter; ${ }^{*}$ significant difference at $\mathrm{P}<0.05$; $^{* *}$ significant difference at $\mathrm{p}<0.01$.
\end{tabular}

Table 2. Time to Peak Torque (ms) between pre- and post-training after 6 weeks of isokinetic eccentric training of knee extensors.

\begin{tabular}{lcc}
\hline \multirow{2}{*}{ Torque } & \multicolumn{2}{c}{ Time to peak torque (ms) } \\
& Pre-training & Post-training \\
\hline Extensors & & \\
\hline Eccentric $30 \%$ & $2723 \pm 755$ & $2185 \pm 219^{*}$ \\
\hline Eccentric $120^{\circ} / \mathrm{s}$ & $951 \pm 368$ & $775 \pm 236$ \\
\hline Flexors & & \\
\hline Eccentric $30 \% \mathrm{~s}$ & $2343 \pm 541$ & $2259 \pm 636$ \\
\hline Eccentric $120^{\circ} / \mathrm{s}$ & $555 \pm 113$ & $528 \pm 75$ \\
\hline
\end{tabular}

* $P=0.003$ (Wilcoxon).

Table 3. Hamstrings/Quadriceps ratio between pre- and post-training in non-dominant limb.

\begin{tabular}{lcccc}
\hline \multirow{2}{*}{ Contraction Modes } & \multicolumn{4}{c}{ Hamstrings/quadriceps ratios (\%) } \\
\hline Isometric & Pre-training & Post-training & t-test (paired) & Difference (\%) \\
\hline Eccentric $30 \%$ & $49.8 \pm 8.3$ & $45.1 \pm 7.8$ & 0.0057 & 10 \\
\hline Eccentric $120 \%$ & $50.4 \pm 7.5$ & $40.3 \pm 7.0$ & $<0.0001$ & 20 \\
\hline
\end{tabular}


Table 4. Comparison of the means of the functional tests before and after 6 weeks of isokinetic eccentric training of the knee extensors.

\begin{tabular}{lccc}
\hline Functional Tests & Pre-training & Post-training & \\
\hline Shuttle run (s) & $13.80 \pm 0.87$ & $13.57 \pm 0.88$ & 0.190 \\
\hline Lateral run $(\mathrm{s})$ & $14.92 \pm 2.24$ & $14.48 \pm 1.47$ & $0.33 \dagger$ \\
\hline Carioca $(\mathrm{s})$ & $19.48 \pm 3.95$ & $16.91 \pm 1.97$ & $<0.01 \dagger$ \\
\hline Pivot diagonal run $(\mathrm{s})$ & $34.58 \pm 3.09$ & $32.40 \pm 2.54$ & $<0.01 \dagger$ \\
\hline Figure-eight run (s) & $16.68 \pm 2.95$ & $16.14 \pm 2.59$ & 0.150 \\
\hline SHDL (m) & $1.95 \pm 0.15$ & $2.02 \pm 0.13$ & $<0.05 \dagger$ \\
\hline SHNDL (m) & $1.96 \pm 0.16$ & $2.05 \pm 0.12$ & $<0.010$ \\
\hline THDL $(\mathrm{m})$ & $5.81 \pm 0.35$ & $5.93 \pm 0.36$ & $<0.05 \dagger$ \\
\hline THNDL $(\mathrm{m})$ & $5.77 \pm 0.32$ & $5.95 \pm 0.35$ & $<0.01 \dagger$ \\
\hline
\end{tabular}

Results: mean \pm stand deviation; SHDL=single hop dominant limb; SHNDL=single hop non-dominant limb; THDL=triple hop dominant limb; THNDL=triple hop non-dominant limb; $s=s e c o n d ; m=m e t e r ; ~ \diamond$ (Wilcoxon); $†$ (t test).

\section{Functional tests}

There were significant differences $(\mathrm{P}<0.01)$ for two of the five agility tests (carioca and pivot diagonal run) when comparing the means of functional tests in pre- and post-eccentric training of the knee extensors (Table 4). For the hop for distance tests, there were significant differences in the single and triple hop for distance tests for both limbs, however the non-dominant limb showed greater significance $(\mathrm{P}<0.01)$ than the dominant limb.

\section{Correlation: MPT versus functional tests}

There were weak correlations $(r \leq 0.5)$ between the MPT of knee extensors and flexors and the functional agility tests for all modes and velocities, in both pre- and post-training. The correlations for the hop for distance tests in pre- and posttraining for both test types (single and triple) were generally weak $(r \leq 0.5)$. However, there was a weak and moderate correlation, in pre-training, between the MPT of knee extensors and the single hop for distance test in the eccentric mode at $30 \% \mathrm{~s}$ and $120^{\circ} / \mathrm{s}$ ( $\mathrm{r}=0.50$ and 0.53 , respectively). There was also a moderate correlation between the MPT of knee extensors and the triple hop for distance test in the eccentric mode at $30^{\circ} / \mathrm{s}$ $(\mathrm{r}=0.56)$. Moderate and strong correlations were also observed between the MPT of knee flexors in the eccentric mode at both velocities and the single hop for distance test $(\mathrm{r}=0.63$ and 0.78 , respectively). In the post-training, the correlation between the MPT of knee flexors, in the eccentric mode, at $120^{\circ}$ /s was also moderate ( $r=0.60$ ), although it was shown to be lower than the correlation seen for the pre-training.

\section{Discussion $: \therefore$.}

The results of the present study showed that peak torque increased after isokinetic eccentric training in all of the contraction modes and velocities analyzed (isometric, and eccentric at $30^{\circ} / \mathrm{s}$ and $120 \% \mathrm{~s}$ ), therefore in agreement with several authors ${ }^{9,28,41-46}$. The greatest torque gain was observed in the eccentric mode at $30^{\circ} / \mathrm{s}$, as supported by previous studies ${ }^{25,26}$, however a torque increment was also observed in the isometric mode and eccentric mode at $120^{\circ} / \mathrm{s}$, a fact also evidenced by Blazevich ${ }^{47}$.

According to several studies, resistance training promotes changes in the neurological system, leading to force gain ${ }^{43,46}$, especially in the first eight weeks, without significant increase in the cross-sectional area of the muscle ${ }^{28}$. Using functional magnetic resonance imaging, Duchateau and Enoka ${ }^{48}$ showed an increase in the modulation of the motor cortex area on muscles of the hand after 3 weeks of training. Although variables such as number, firing rate and synchronization of the active motor units were not analyzed in the current study, it is possible to assume that the torque gained in response to the training protocol (6 weeks) is a result of the changes in muscle recruitment patterns ${ }^{9,44,45}$.

The flexor peak torque was also increased in the eccentric mode at $30 \%$, which indicates that this muscle group plays a role in the eccentric contraction of the extensors. This gain may be explained by the active (isometric) exercise of the contralateral flexors during the eccentric training of the extensors. Although the exercise was not monitored by electromyography, it was possible to visually identify an isometric contraction of the contralateral flexors during the eccentric training of the extensors.

The results showed that, although TPT tended to decrease in all analyzed modes and velocities, the relationship was specific to the mode and velocity of training (eccentric at $30^{\circ} / \mathrm{s}$ ). This is probably associated with force gain and improved motor unit recruitment, because a low TPT at the beginning of training was followed by a substantial peak torque gain in the eccentric mode at $30^{\circ} / \mathrm{s}$. In a study on the activation patterns of knee extensors, McHugh et al. ${ }^{49}$ verified that a lower TPT 
is related to the fact that isokinetic eccentric exercise requires higher recruitment of type II muscle fibers. Similarly, Miller et al. ${ }^{50}$ demonstrated that TPT was significantly lower after eccentric training when compared to concentric training for both knee extensors and flexors, indicating improved neuromuscular function.

The conventional H/Q ratio was used because it was not possible to calculate the functional H/Q ratio due to the lack of records for concentric peak torques during evaluations. The conventional $\mathrm{H} / \mathrm{Q}$ is used as a standard test of knee muscle balance $2,12,13,16,32,50-53$. For the comparison of the H/Q ratio between pre- and post-training, the training protocol lead to a decrease of $20 \%, 13 \%$ and $10 \%$ in the eccentric mode at $30 \%$ s, $120^{\circ} / \mathrm{s}$ and isometric mode, respectively. These decreases in $\mathrm{H} / \mathrm{Q}$ ratio were due to the increased extensor peak torque rather than the decreased flexor peak torque. Although there was a gain in the knee flexor torque, this gain was lower than the gain recorded for the knee extensors, therefore leading to a decrease in the antagonist/agonist ratio. In a review study on the contribution of the eccentric contraction to injury, prevention, rehabilitation and sports, LaStayo et al. ${ }^{5}$ reported that this contraction, when exclusively applied to a single muscle group, may compromise knee stability due to changes in the $\mathrm{H} / \mathrm{Q}$ ratio.

Despite this significant decrease, the lower rate of flexor torque represented $40 \%$ of the extensor torque for all analyzed contraction modes. However, this percentage is within the range of variability (40-80\%) described in many other studies on $\mathrm{H} / \mathrm{Q}$ ratio, depending on the studied population, age and gender $^{7,52}$. Therefore, in spite of the fact that the current protocol only elicited the knee extensors and lead to a decrease in $\mathrm{H} / \mathrm{Q}$ ratio, the percentage of the ratio seen here $(<40 \%)$ does not compromise the stability of the knee joint.

It can be observed in the present results that the three torque variables (MPT, TPT and H/Q ratio) showed more significant differences for the specific training mode and speed of eccentric training at $30^{\circ} / \mathrm{s}$, which characterizes the principle of training specificity when compared to the other assessed modes and speeds ${ }^{25,54}$. Duchateau and Enoka ${ }^{48}$ corroborate the results of the current study by demonstrating that the performance in functional tests is improved to a maximum level in similar tasks and can be affected by contraction mode, load, velocity and posture. Indeed, the distances in both types of hop for distance (single and triple) may have increased due to a greater similarity to the task of the training protocol (high force, low velocity). In contrast, an improved performance was only observed in two (carioca and pivot diagonal run) of the five agility tests. Furthermore, Kraemer et al. ${ }^{9}$ demonstrated that strength training alone elicits no significant improvement in running performance. Also, these same authors verified that tests conducted at velocities above $180^{\circ}$ /s were better indicators of agility, thus being more closely related to knee joint function.

In light of these considerations, it is possible that the results obtained after training would have been more significant, especially for the agility tests, if the training protocol had been conducted at a medium velocity $\left(\cong 180^{\circ} / \mathrm{s}\right)$ in the concentric and eccentric modes because positive (shortening) and negative (lengthening) work of the knee muscles was observed in the completion of all the functional tests used in the present study. Sheppard and Young ${ }^{20}$ argue that the ability to perform an agile movement involves not only physical but also cognitive factors, suggesting that the decreased time in functional tests (such as the carioca and pivot diagonal run) as well as the increased distance in the hop for distance tests may be due to a combination of both factors. However, this hypothesis may be rejected as the subjects performed the tests only twice (preand post-training), with a 6-week interval between them. Furthermore, in the post-training evaluation, the subjects asked the examiner to show them how to perform the test as they could not remember how to do it.

The manual timing used for the agility tests, although recorded by the same examiner, probably influenced the results because it is an evaluator-dependent measure, therefore not as reliable as a record obtained by an electronic synchronization system or photo-cells. Another factor that may also have influenced the results of this study was the total number of tests ( 5 runs and 2 hops), because each of the tests was performed three times consecutively. Unlike the present study, most of the studies found in the literature ${ }^{34-39,48,55}$ used only one or two trials, while a few ${ }^{18,19,33}$ used a maximum of five trials to combine activities of agility and hop.

There is considerable disagreement in the literature regarding which muscle group is most involved in the functional movements of the knee. Li et al. ${ }^{56}$ found correlations between the knee flexor forces and functional abilities, while other authors ${ }^{57,58}$ found this correlation only with the extensors. However, these correlations were classified as weak or moderate.

The results of the present study are in agreement with the literature because there were weak correlations between functional tests and torque for both knee extensors and flexors, however most studies included subjects with deficient or reconstructed ACLs. Other studies included healthy subjects ${ }^{23}$ or athletes ${ }^{13,16,24}$ in their sample, and although they found similar results to those of the present study (weak and moderate correlation), the discussion is hampered by differences in methodology such as closed kinetic chain ${ }^{23}$ or open kinetic chain ${ }^{13,16,24}$, linear isokinetic test ${ }^{23}$ or angular isokinetic test ${ }^{13,14,16,24}$, training protocol (mode of contraction, muscle group, number of 
repetitions, frequency, duration, time to rest, speed of contraction, etc.) and quantity and type of functional tests used in the relationship analysis ${ }^{59}$.

The fact that isokinetic tests are performed in open kinetic chain and functional tests are performed in closed kinetic chain may have influenced the relationship analysis, which suggests that the muscles of the joints proximal and distal to the knee (hip and ankle) could increase the performance of functional tests ${ }^{49}$. The low speed of contraction used in the training protocol $\left(30^{\circ} / \mathrm{s}\right)$ when compared with the velocities of contraction developed in the various functional tests $\left(\geq 60^{\circ} / \mathrm{s}\right)^{2,13,15,50,51}$ and the lack of evaluation in the concentric mode ${ }^{15,23,24}$ may also have influenced the results. Another factor in our study that could justify the moderate correlations between the torque and hop tests would be the similarity between the speed of movement in the training $\left(30^{\circ} / \mathrm{s}\right)$ and the specific hop task. Thus, the weak correlations with the agility tests (runs) can also be explained by the difference in speed between the tasks.

\section{Conclusions : $:$.}

Although the training protocol elicited a substantial increase in the extensor peak torque, especially at $30^{\circ} / \mathrm{s}$, along with improved performance in most of the functional tests (carioca and pivot diagonal run, and single and triple hop), the hypothesis that a strong correlation would be observed between these variables was not confirmed. This suggests that the functional tests and isokinetic tests assess different measures, and it seems that the combination of measures is important for a full assessment of functional capacity.

\section{Acknowledgements $: \because 8$}

To Fundação de Amparo à Pesquisa do Estado de São Paulo (FAPESP), Conselho Nacional de Desenvolvimento Científico e Tecnológico (CNPq) and Coordenação de Aperfeiçoamento de Pessoal de Nível Superior (CAPES) for their financial support.

\section{References}

1. Aquino MA, Leme LE, Amatuzzi MM, Greve JM, Terreri ASAP, Andrusaitis FR, et al. Isokinetic assessment of knee flexor/extensor muscular strength in elderly women. Rev Hosp Clin Fac Med Univ São Paulo. 2002;57(4):131-4.

2. Rosene JM, Forgarty TD, Mahaffey BL. Isokinetic hamstrings: quadriceps ratios in intercollegiate athletes. J Athl Train. 2001;36(4):378-83

3. Kannus P. Isokinetic evaluation of muscular performance: implications for muscle testing and rehabilitation. Int J Sports Med. 1994;15 Suppl 1:S11-8.

4. Siqueira CM, Pelegrini FR, Fontana MF, Greve JM. Isokinetic dynamometry of knee flexors and extensors: comparative study among non-athletes, jumper athletes and runner athletes. Rev Hosp Clin Fac Med Univ São Paulo. 2002;57(1):19-24.

5. LaStayo PC, Woolf JM, Lewek MD, Snyder-Mackler L, Reich T, Lindstedt SL. Eccentric muscle contractions: their contribution to injury, prevention, rehabilitation and sport. J Orthop Sports Phys Ther. 2003;33(10):557-71.

6. Goldspink G. Molecular mechanisms involved in the determination of muscle fiber mass and phenotype. Adv Exerc Sports Physiol. 1999;5(2):27-39.

7. Seger JY, Thorstensson A. Effects of eccentric versus concentric training on thigh muscle strength and EMG. Int J Sports Med. 2005;26(1):45-52.

8. Clebis NK, Natali MRM. Lesões musculares provocadas por exercícios excêntricos. Rev Bras Ciênc Mov. 2001;9(4):47-53.

9. Kraemer WJ, Adams K, Cafarelli E, Dudley GA, Dooly C, Feigenbaum MS, et al. Progression models in resistance training for healthy adults. Med Sci Sports Exerc. 2002;34:364-80.

10. Fitts RH. Effects of regular exercise training on skeletal muscle contractile function. Am J Phys Med Rehabil. 2003;82(4):320-31

11. Widrick JJ, Stelzer JE, Shoepe TC, Garner DP. Functional properties of human muscle fibers after short-term resistance exercise training. Am J Physiol Regul Integr Comp Physiol. 2002;283(2):R408-16

12. Kellis E, Baltzopoulos V. Muscle activation differences between eccentric and concentric isokinetic exercise. Med Sci Sports Exerc. 1998;30(11):1616-23.

13. Dauty M, Potiron-Josse M. Correlations and differences of performance between soccer players, professionals, young players and amateurs, from the 10-meter sprint test and knee isokinetic assessment. Sci Sports. 2004;19(2):75-9.
14. Newton RU, Gerber A, Nimphius S, Shim JK, Doan BK, Robertson M, et al. Determination of functional strength imbalance of the lower extremities. J Strength Cond Res. 2006;20(4): 971-7.

15. Croce RV, Pitetti KH, Horvat M, Miller J. Peak torque, average power, and Hamstrings/Quadriceps ratios in nondisabled adults and adults with mental retardation. Arch Phys Med Rehabil. 1996;77(4):369-72

16. Jidovtseff B, Croisier JL, Mordant B, Crielaard JM. Isokinetic profile of knee flexors and extensors in a jumpers population. Sci Sports. 2005;20(5-6):304-7.

17. Keskula DR, Duncan JB, Davis VL, Finley PW. Functional outcome measures for knee dysfunction assessment. J Athl Train. 1996;31(2):105-10.

18. Keays SL, Bullock-Saxton JE, Keays AC, Newcombe P. Muscle strength and function before and after anterior cruciate ligament reconstruction using semitendonosus and gracilis. Knee. 2001;8(3):229-34.

19. Keays SL, Bullock-Saxton JE, Newcombe P, Keays AC. The relationship between knee strength and functional stability before and after anterior cruciate ligament reconstruction. J Orthop Res. 2003;21(2):231-7.

20. Sheppard JM, Young WB. Agility literature review: classifications, training and testing. J Sports Sci. 2006;24(9):919-32

21. Phillips N, Benjamin M, Everett T, Van Deursen RWM. Outcome and progression measures in rehabilitation following anterior cruciate ligament injury. Phys Ther Sport. 2000;1(1): 106-18.

22. Campenella B, Mattacola CG, Kimura IF. Effect of visual feedback and verbal encouragement on concentric quadriceps and hamstrings peak torque of males and females. Isokinet Exerc Sci. 2000;8:1-6.

23. Manske RC, Smith BS, Rogers ME, Wyatt FB. Closed kinetic chain (linear) isokinetic testing: relationships to functional testing. Isokinet Exerc Sci. 2003;11:171-9.

24. D'Alessandro RL, Silveira EAP, Anjos MTS, Silva AA, Fonseca ST. Análise da associação entre dinamometria isocinética da articulação do joelho e o salto horizontal unipodal, hop test, em atletas de voleibol. Rev Bras Med Esporte. 2005;11(5):271-5.

25. Seger JY, Arvidsson B, Thorstensson A. Specific effects of eccentric and concentric training on muscle strength and morphology in humans. Eur J Appl Physiol. 1998;79(1):49-57. 
26. Kellis $E$, Baltzopoulus $V$. The effects of the antagonist muscle force on intersegmental loading during isokinetic efforts of the knee extensors. J Biomech. 1999;32(1):19-25

27. Gobbi LTB, Secco CR, Marins FHP. Preferência pedal: comportamento locomotor em terreno regular. In: Teixeira LA. Avanços em comportamento motor. São Paulo: Movimento; 2001. p. $225-47$

28. Knight CA, Kamen G. Adaptations in muscular activation of the knee extensor muscles with strength training in young and older adults. J Electromyogr Kinesiol. 2001;11(6): 405-12.

29. Dvir Z. Isokinetics: muscle testing, interpretation and clinical applications. Edinburgh: Churchill Livingstone; 2004.

30. Davies GJ, Ellenbecker TS. Aplicação da isocinética nos testes e na reabilitação. In: Andrews JR, Harrelson GL, Wilk KE. Reabilitação física das lesões desportivas. $2^{a}$ ed. Rio de Janeiro: Guanabara Koogan; 2000. p. 160-88.

31. Wilk KE, Arrigo CA, Andrews JR. Standardized isokinetic testing protocol for the throwing shoulder: the throwers series. Isokinet Exerc Sci. 1991;1:63-71.

32. Aagaard P, Simonsen EB, Magnusson SP, Larsson B, Dyhre-Poulsen P. A new concept for isokinetic hamstring: quadriceps muscle strength ratio. Am J Sports Med. 1998;26(2): 231-37.

33. Ortiz A, Olson SL, Roddey TS, Morales J. Reliability of selected physical performance tests in young adult women. J Strength Cond Res. 2005;19(1):39-44.

34. Hasebe $Y$, Tanabe $Y$, Yasuda K. Anterior-Cruciate-Ligament reconstruction using doubled hamstring-tendon autograft. J Sport Rehabil 2005;14(4):279-93

35. Augustsson J, Thomeé R, Karlsson J. Ability of a new hop test to determine functional deficits after anterior cruciate ligament reconstruction. Knee Surg Sports Traumatol Arthrosc. 2004;12(5):350-6

36. McDevitt ER, Taylor DC, Miller MD, Gerber JP, Ziemke G, Hinkin D, et al. Functional bracing after anterior cruciate ligament reconstruction - a prospective, randomized and multicenter study. Am J Sports Med. 2004;32(8):1887-92.

37. Swanik CB, Lephart SM, Swanik KA, Stone DA, Fu FH. Neuromuscular dynamic restraint in women with anterior cruciate ligament injuries. Clin Orthop Relat Res. 2004;425: 189-99.

38. Pollet V, Barrat D, Meirhaeghe E, Vaes P, Handelberg F. The role of the Rolimeter in quantifying knee instability compared to the functional outcome of ACL-reconstructed versus conservativelytreated knees. Knee Surg Sports Traumatol Arthrosc. 2005;13(1):12-8.

39. O'Donnell S, Thomas SG, Marks P. Improving the sensitivity of the hop index in patients with an ACL deficient knee by transforming the hop distance scores. BMC Musculoskelet Disord. 2006;7(9):1-6

40. Holm I, Fosdahl MA, Friis A, Risberg MA, Myklebust G, Steen H. Effect of neuromuscular training on proprioception, balance, muscle strength, and lower limb function in female team handball players. Clin J Sport Med. 2004;14(2):88-94

41. Hickson RC, Hikada K, Foster C. Skeletal muscle fiber type, resistance training, and strengthrelated performance. Med Sci Sports Exerc. 1994;26(5):593-8.

42. Ploutz LL, Tesch PA, Biro RL, Dudley GA. Effect of resistance training on muscle use during exercise. J Appl Physiol. 1994;76(4):1675-81.
43. Staron RS, Karapondo DL, Kraemer WJ, Fry AC, Gordon SE, Farkel JE, et al. Skeletal muscle adaptations during early phase of heavy-resistance training in men and women. J Appl Physiol. 1994;76(3):1247-55

44. Carroll TJ, Stephan R, Carson RG. Neural adaptations to resistance training: implication for movement control. Sports Med. 2001;31(12):829-40.

45. Lieber RL. Skeletal muscle: structure, function and plasticity - the physiological basis of rehabilitation. $2^{\mathrm{a}}$ ed. Baltimore: Willians \& Willians; 2002

46. Tomiya A, Aizawa T, Nagatomi R, Sensui H, Kokubun S. Myofibers Express IL-6 after eccentric exercise. Am J Sports Med. 2004;32(2):503-8.

47. Blazevich AJ. Effect of movement pattern and velocity of strength training exercise on training adaptations during concurrent resistance and sprint/jump training [thesis]. Lismore (NSW): School of Exercise Science and Sport Management - Southern Cross University; 2001.

48. Duchateau J, Enoka RM. Neural adaptation with chronic activity patterns in able-bodied humans. Am J Phys Med Rehabil. 2002;81(11 Suppl):S17-27

49. McHugh MP, Tyler TF, Greenberg SC, Gleim GW. Differences in activation patterns between eccentric and concentric quadriceps contractions. J Sports Sci. 2002;20(2):83-91.

50. Miller LE, Pierson LM, Nickols-Richardson SM, Wootten DF, Selmon SE, Ramp WK, et al. Knee extensor and flexor torque development with concentric and eccentric isokinetic training. Res $Q$ Exerc Sport. 2006;77(1):58-63.

51. Calmels PM, Nellen M, van der Borner I, Jourdin P, Minaire P. Concentric and eccentric isokinetic assessment of flexor-extensor torque ratios at the hip, knee, and ankle in a sample population of healthy subjects. Arch Phys Med Rehabil. 1997;78(11):1224-30.

52. Hiemstra LA, Webber S, MacDonald PB, Kriellaars DJ. Hamstring and quadriceps strength balance in normal and hamstring anterior cruciate ligament-reconstructed subjects. Clin J Sport Med. 2004;14(5):274-80.

53. Tourny-Chollet C, Leroy D. Conventional vs. dynamic hamstrings-quadriceps strength ratios: a comparison between players and sedentary subjects. Isokinet Exerc Sci. 2002;10:183-92.

54. Folland JP, Williams AG. The adaptations to strength training: morphological and neurological contributions to increased strength. Sports Med. 2007;37(2):145-68.

55. Aune AK, Holm I, Risberg MA, Jensen HK, Steen H. Four-strand hamstring tendon autograft compared with patellar tendon-bone autograft for Anterior Cruciate Ligament reconstruction: a randomized study with two-year follow-up. Am J Sports Med. 2001;29(6):722-8.

56. Li RC, Maffulli N, Hsu YC, Chan KM. Isokinetic strength of the quadriceps and hamstrings and functional ability of anterior cruciate ligament deficient knees in recreational athletes. Br J Sports Med. 1996;30:161-4.

57. Wilk KE, Romaniello WT, Soscia SM, Arrigo CA, Andrews JR. The relationship between subjective knee scores, isokinetic testing and functional testing in the ACL- reconstructed knee. J Orthop Sports Phys Ther. 1994;20(2):60-73

58. Itoh H, Kurosaka M, Yoshiya S, Ichihashi N, Mizuno K. Evaluation of functional deficits determined by four different hop tests in patients with anterior cruciate ligament deficiency. Knee Surg Sports Traumatol Arthrosc. 1998;6(4):241-5

59. Özçakar L, Kunduracyoolu B, Cetin A, Ülkar B, Guner R, Hascelik Z. Comprehensive isokinetic knee measurements and quadriceps tendon evaluations in footballers for assessing functional performance. Br J sports Med. 2003;37(6):507-10. 